\title{
Resíduos farmacêuticos: riscos ambientais do descarte inadequado de medicamentos
}

O consumo exacerbado de fármacos aliado à falta de conscientização sobre o descarte correto apresenta riscos ambientais e à saúde pública. Desta forma, o trabalho visa expor os riscos ambientais do descarte inadequado de medicamentos pela população brasileira. Por meio da pesquisa bibliográfica, foi realizada uma análise crítica dos impactos ambientais negativos dos resíduos farmacêuticos e dos hábitos da população quanto ao descarte desses resíduos. Como resultado da pesquisa, pode-se concluir que a maioria da população realiza o descarte de forma errônea (lixo comum, pia, vaso sanitário) e carece de informação sobre a forma correta (logística reversa). Essa atitude apresenta riscos ambientais, tais como: contaminação do solo, poluição do ar, qualidade da água, morte de espécies aquáticas e surgimento de bactérias resistentes.

Palavras-chave: Resíduos Fármacos; Saúde Pública; Risco Ambiental.

\section{Pharmaceutical waste: environmental risks of improper disposal of medicines}

The exacerbated consumption of drugs combined with the lack of awareness about the correct disposal present environmental and public health risks. In this way, the work aims to expose the environmental risks of inappropriate disposal of medicines by the Brazilian population. Through bibliographic research, a critical analysis of the negative environmental impacts of pharmaceutical residues and the habits of the population regarding the disposal of these residues was carried out. As a result of the research, it can be concluded that the majority of the population performs the disposal in an erroneous way (common garbage, sink, toilet bowl) and lacks information about the correct way (reverse logistics). This attitude presents environmental risks, such as: soil contamination, air pollution, water quality, death of aquatic species and the emergence of resistant bacteria.

Keywords: Pharmaceutical Residues; Public health; Environmental Risk.

Topic: Desenvolvimento, Sustentabilidade e Meio Ambiente

Reviewed anonymously in the process of blind peer.

Flávia Monaco Vieira (iD)

Universidade La Salle, Brasil

http://lattes.cnpq.br/3124206982085534

http://orcid.org/0000-0003-0851-6506

flavia.201910304@unilasalle.edu.br
Received: $10 / 11 / 2020$

Approved: 15/02/2021
Referencing this:

VIEIRA, F. M.. Resíduos farmacêuticos: riscos ambientais do descarte inadequado de medicamentos. Natural Resources, v.11, n.1, p.74-81, 2021. DOI: http://doi.org/10.6008/CBPC2237-9290.2021.001.0010 


\section{INTRODUÇÃO}

Os medicamentos contribuem para a qualidade de vida, sendo essenciais para o tratamento de doenças; no entanto, esses mesmos produtos químicos apresentam uma série de consequências indesejadas quando liberados no meio ambiente (VATOVEC et al., 2017).

Devido ao desconhecimento do manejo adequado dos resíduos fármacos, por parte da população e, muitas vezes, pela falta de informação sobre os impactos causados ao meio ambiente e a saúde pública, os medicamentos em desuso ou vencidos acabam sendo descartados diretamente no lixo comum ou em efluentes (vaso sanitário, ralo, pias).

A geração de resíduos constitui-se um grande desafio e "os resíduos dos serviços de saúde - RSS se inserem dentro desta problemática e vêm assumindo grande importância nos últimos anos" (BRASIL, 2006).

O objetivo deste trabalho é expor os riscos ambientais do descarte inadequado de medicamentos, por parte da população brasileira, sendo abordado inicialmente a problemática da geração dos resíduos sólidos, classificação dos resíduos de medicamentos e as consequências deste descarte no meio ambiente. Esta pesquisa visa, ainda, contribuir para a discussão do tema e reflexão de possíveis soluções.

\section{METODOLOGIA}

O desenvolvimento do trabalho foi realizado por meio de pesquisa definida como revisão bibliográfica (MARCONI et al., 2010), através de textos publicados em revistas científicas, que constituiu a principal fonte de pesquisa. Outras fontes utilizadas foram dissertações de mestrado, legislação e trabalhos científicos apresentados em Congressos.

A coleta de dados bibliográficos permitiu, juntamente com uma análise crítica, expor os riscos ambientais causados pelo descarte inadequado de medicamentos e apoiados nas constatações de estudos realizados por outros pesquisadores, demonstrar os hábitos e informações da população quanto ao descarte desses resíduos. Utilizaram-se quatro estudos para delinear a situação brasileira:

Quadro 1: Estudos sobre descarte de medicamentos.

\begin{tabular}{|l|l|l|}
\hline Autores & Título & Ano \\
\hline CRUZ et al. & Descarte de medicamentos em municípios do Vale do Jequitinhonha, Minas Gerais, Brasil. & 2017 \\
\hline GASPARINI et al. & Estudo do descarte de medicamentos e consciência ambiental no município de Catanduva- SP. & 2011 \\
\hline MIRANDA et al. & $\begin{array}{l}\text { Avaliação do conhecimento dos consumidores de duas cidades da Grande SP, Brasil, Sobre os } \\
\text { impactos causados pelo descarte incorreto de medicamentos. }\end{array}$ & 2018 \\
\hline RAMOS et al. & Descarte de medicamentos: Uma reflexão sobre os possíveis riscos sanitários e ambientais. & 2017 \\
\hline
\end{tabular}

\section{DISCUSSÃO TEÓRICA}

\section{Resíduos Sólidos}

O crescimento populacional, urbanização, modelos de produção e consumo contribuem para o aumento da geração de resíduos sólidos, sendo este um dos importantes desafios a serem enfrentados pela sociedade moderna.

Estima-se que atualmente a taxa de crescimento de resíduos sólidos urbanos seja mais rápida que a taxa da urbanização. As estimativas globais indicaram que, em 2002, 2,9 bilhões de residentes urbanos 
geravam cerca de 0,64 $\mathrm{kg}$ de lixo por pessoa por dia e, em 2012, esse número aumentou para 1,2 kg por pessoa por dia, com uma população urbana total de 3 bilhões. Projeta-se que até 2025 haverá cerca de 4,3 bilhões de moradores urbanos que, em média, gerarão 1,42 kg de resíduos por dia (ZIRABA et al., 2016).

Frente às demandas ambientais, sociais e econômicas, questões sobre a problemática dos resíduos passam a integrar a pauta das políticas públicas. No Brasil, em 2010, foi implantada a Política Nacional de Resíduos Sólidos - PNRS instituída pela Lei 12.395,10, que prevê: a prevenção e a redução na geração de resíduos, tendo como proposta a prática de hábitos de consumo sustentável e um conjunto de instrumentos para propiciar o aumento da reciclagem e da reutilização dos resíduos sólidos (aquilo que tem valor econômico e pode ser reciclado ou reaproveitado) e a destinação ambientalmente adequada dos rejeitos (aquilo que não pode ser reciclado ou reutilizado), (BRASIL, 2019). Antes da PNRS, Balbino et al. (2012) destacam que: “[...] esses resíduos sólidos eram negligenciados pelo poder público, legisladores e administradores".

Resíduo sólido: Material, substância, objeto ou bem descartado resultante de atividades humanas em sociedade, a cuja destinação final se procede, se propõe proceder ou se está obrigado a proceder, nos estados sólido ou semissólido, bem como gases contidos em recipientes e líquidos cujas particularidades tornem inviável o seu lançamento na rede pública de esgotos ou em corpos d'água, ou exijam para isso soluções técnica ou economicamente inviáveis em face da melhor tecnologia disponível. (BRASIL, 2010)

A PNRS classificou os resíduos sólidos quanto à sua origem e periculosidade. Os resíduos farmacológicos são oriundos dos serviços de saúde e considerados perigosos, por apresentarem características como toxicidade, patogenicidade, carcionogenicidade, teratogenicidade e mutagenicidade (BRASIL, 2010).

Os resíduos de serviços de saúde são parte importante do total de resíduos sólidos urbanos, não necessariamente pela quantidade gerada (cerca de $1 \%$ a $3 \%$ do total), mas pelo potencial de risco que representam à saúde e ao meio ambiente. (BRASIL, 2006)

A Associação Brasileira de Normas e Técnicas (ABNT), por meio da NBR 12.808 de 1993, já apresentava a classificação dos resíduos de serviço de saúde, no entanto sem trazer grande contribuição quanto ao gerenciamento ambiental adequado. A classificação é feita por classes, sendo: Classe A (Resíduos infectantes - biológico, sangue, cirúrgico, perfurante, animal contaminado, assistência ao paciente); Classe B (Resíduo especial - rejeito radioativo, resíduo farmacêutico e resíduo químico perigoso) e Classe C (Resíduo Comum - todos aqueles não enquadrados nos tipos A e B, ou seja, não oferecem risco adicional à saúde pública). Os resíduos farmacêuticos (classe B) são compostos por medicamentos vencidos, contaminado, interditado ou não utilizado (ABNT, 1993).

A Resolução RDC ANVISA no 222 de 2018 (alterou a RDC n 306/2004), que dispõe sobre o Regulamento Técnico para o gerenciamento de resíduos de serviço de saúde, apresenta de forma distinta a classificação dos resíduos de serviço de saúde, sendo: grupo A (resíduos com risco biológicos), grupo B (resíduos com risco químico), grupo $\mathrm{C}$ (rejeitos radioativos), grupo $\mathrm{D}$ (resíduos comuns), e grupo $\mathrm{E}$ (resíduos perfuro cortantes).

Os resíduos farmacêuticos (grupo B) devem ser identificados por meio de símbolo e frase de risco associado à periculosidade do resíduo químico. A figura 1 apresenta o símbolo para os resíduos de 
medicamentos.

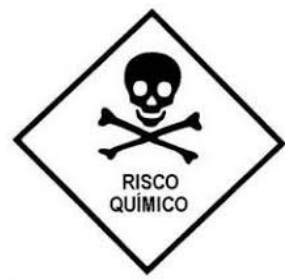

Figura 1: Identificação de Risco Químico. Fonte: RDC ANVISA no 222/2018.

\section{Medicamentos e geração de resíduos}

O Brasil é um grande consumidor de medicamentos (SOUZA et al., 2015; MIRANDA et al., 2018), e muitos dos medicamentos adquiridos são utilizados sem considerar o prazo de validade ou são descartados de maneira inadequada, gerando um problema ambiental e de saúde pública (GASPARINI et al., 2011). Além disso, à medida que a população envelhece, tende a aumentar a dependência de produtos farmacêuticos (VATOVEC et al., 2017).

Miranda et al. (2018) apontam que, "[...] com a crescente urbanização do país, ocorre o surgimento de doenças emergentes e junto com elas a produção e o consumo de medicamentos pela população". Em decorrência do avanço tecnológico da indústria farmacêutica novos medicamentos são lançados, contribuindo significativamente para a geração de resíduos, que incrementa a "[...] variedade e quantidade de fármacos à disposição da população para tratamento de doenças, resultando em novas embalagens e compostos químicos detentores da capacidade de degradar o meio ambiente caso não recebam tratamento adequado" (COSTA, 2019).

Balbino et al. (2012) propõem uma reflexão sobre o grande volume de resíduos sólidos de serviço de saúde produzidos no mundo, especialmente quanto aos gerados pelo desperdício. Entre os fatores que contribuem para o acúmulo de medicamentos e posteriormente tornam-se resíduos que necessitam de descarte adequado, Costa (2019) destaca,

O descuido dos pacientes ao tratar doenças quando os medicamentos receitados não são utilizados até o fim; o fácil acesso sem necessidade de receita médica; a cultura de automedicação; a ausência de sistemas de fracionamento de medicamentos para fornecer apenas quantias adequadas ao tratamento; a não verificação da validade na compra de medicamentos [...]

Com a evolução da ciência médica, métodos de diagnóstico e tratamento moderno, novos materiais, substâncias e equipamentos, com presença de componentes mais complexos devem ser considerados na avaliação dos riscos ambientais derivados dos resíduos farmacêuticos. Sendo assim, os resíduos do serviço de saúde "[...] merecem atenção especial em todas as suas fases de manejo (segregação, condicionamento, armazenamento, coleta, transporte, tratamento e disposição final) em decorrência dos imediatos e graves riscos que podem oferecer" (BRASIL, 2006).

O consumo exacerbado de fármacos alinhados à falta de conscientização quanto ao descarte correto dos medicamentos apresenta risco ambiental, segundo Costa (2019) "[...] podem degradar a qualidade do solo, águas superficiais, águas subterrâneas e apresentam riscos à saúde humana". "[...] oferecem risco 
quando gerenciados de forma inadequada, favorecendo a propagação de doenças e degradação ambiental", e ainda de acordo Miranda et al. (2018) ocasiona "[...] a morte de espécies aquáticas pela toxicidade do efluente de esgoto, surgimento de bactérias resistentes, além de feminização de peixes com alterações de ecossistemas inteiros".

Quanto aos riscos ao meio ambiente destaca-se o potencial de contaminação do solo, das águas superficiais e subterrâneas pelo lançamento de RSS em lixões ou aterros controlados [...] há o risco de contaminação do ar, dada quando os RSS são tratados pelo processo de incineração descontrolado que emite poluentes para a atmosfera contendo, por exemplo, dioxinas e furanos. (BRASIL, 2006)

Pode-se observar a relevância dos impactos ambientais, oriunda do descarte de medicamentos no meio ambiente, os quais acabam afetando diferentes ecossistemas. Para Souza et al. (2012), "[...]fatos especialmente preocupantes referem-se aos medicamentos que podem causar dependências físicas ou psíquicas; aos antibióticos; hormônios; anestésicos; antilipêmicos; meios de contrate de raios- $\mathrm{X}$; antiinflamatórios, entre outras substâncias".

Os resíduos fármacos necessitam de tratamento específico, não podendo ser descartados junto a resíduos comuns, incluindo: os medicamentos vencidos; não utilizados totalmente em tratamentos; impróprios para consumo; e afins (COSTA, 2019).

Entre os princípios e instrumentos introduzidos pela Política Nacional de Resíduos Sólidos constam a responsabilidade compartilhada pelo ciclo de vida dos produtos e a logística reversa.

Entende-se logística reversa como um instrumento de desenvolvimento econômico e social caracterizado pelo conjunto de ações, procedimentos e meios destinados a viabilizar a coleta e a restituição dos resíduos sólidos ao setor empresarial, para reaproveitamento, em seu ciclo ou em outros ciclos produtivos, ou outra destinação final ambientalmente adequada. (CAMPANHER, 2016)

Apesar de a Lei estabelecer o Plano de Gerenciamento de Resíduos de Serviço de Saúde (PGRSS) aos seus geradores (como farmácias e drogarias) não houve a obrigatoriedade destes recolherem os fármacos que sobram de seus clientes, o que favorece o descarte incorreto por parte da população.

O Governo Federal, visando contornar essa situação, publicou em novembro de 2018 a minuta de decreto que regulamenta a logística reversa de medicamentos em todo território nacional. $\mathrm{O}$ texto da minuta versa de forma detalhada sobre: a responsabilidade de toda a cadeia farmacêutica desde o importador até os consumidores, padroniza o dispensador contentor, equipamento destinado a receber e armazenar medicamentos vencidos ou em desuso, institui quantidade de dispensadores contentores quanto a população de um município, detalha normas e instruções de uso do dispensador, determina farmácias como locais de instalação de dispensadores contentores, dentre outras informações (COSTA, 2019).

Enquanto o decreto não vigorar, algumas iniciativas estaduais e municipais foram tomadas como solução para o descarte final dos medicamentos. No Rio Grande de Sul, as cidades de Passo Fundo (através da Lei Ordinária no 4.462/2007) e Porto Alegre (através da Lei Ordinária no 11.329/2012) apresentaram avanços na obrigatoriedade das farmácias receberem e acondicionarem os medicamentos e suas embalagens, bem como providenciar o destino ambientalmente adequado.

A logística reserva apresenta-se como uma solução para o recolhimento dos resíduos de 
medicamentos, gerados por parte da população, onde as farmácias podem atuar como pontos de recolhimentos, além de estimularem o uso racional e orientarem a forma correra de descarte de medicamentos em desuso ou vencidos. O êxito na implantação da logística reversa de medicamentos dependerá do engajamento do governo, cadeia produtiva farmacêutica e sociedade (CAMPANHER, 2016).

\section{Situação Brasileira e possíveis soluções}

Estudos realizados em diferentes regiões brasileiras demonstraram a questão referente aos resíduos fármacos: grande consumo de medicamos, descarte inapropriado e falta de informação de como realizar o descarte correto.

No município de Catanduva-SP, Gasparini et al. (2011) estudaram sobre o acúmulo de medicamentos e seu descarte, e avaliação da consciência das pessoas sobre o impacto ambiental causado pelo descarte inadequado e se já haviam recebido alguma informação sobre o descarte correto. Os autores concluíram que a maioria dos entrevistados $(92,75 \%)$ possui medicamentos em casa, e alguns possuem medicamentos vendidos $(30,45 \%)$ e as sobras de medicamentos são descartadas no lixo (30,45\%). Dos entrevistados $(80,4 \%)$ acha que essa atitude causa problemas ambientais, e $(84,55 \%)$ relatam nunca terem recebido nenhuma informação sobre esse assunto.

O estudo de Cruz et al. (2017) investigou as formas de descarte de medicamentos e o conhecimento sobre as corretas formas de destino pelas famílias de crianças e adolescentes residentes em áreas urbanas do Vale do Jequitinhonha, situado na região norte de Minas Gerais, onde constataram que, em relação aos medicamentos vencidos, $88,5 \%$ dos pesquisados descartavam no ambiente e $88,8 \%$ disseram nunca ter recebido informações quanto à forma correta de descarte dos medicamentos.

Ramos et al. (2017) analisaram a forma como a população do Distrito Federal realiza o descarte de medicamentos e a reflexão sobre os possíveis riscos sanitários e ambientais de exposição desses medicamentos descartados. Entre outros dados, a pesquisa concluiu que a maioria dos entrevistados (61,8\%) faz uso de medicamentos; $78,9 \%$ fazem descarte de medicamentos, principalmente pela expiração do prazo de validade (62,9\%). A maioria declarou nunca ter recebido informação sobre o descarte adequado de medicamentos $(80,7 \%)$. O descarte de medicamentos foi realizado pela maioria, na última vez, juntamente com resíduo comum $(73,6 \%)$, outros afirmaram ter descartado na pia $(8,7 \%)$ ou no vaso sanitário, que representou $(7,0 \%)$.

A pesquisa de Miranda et al. (2018) avaliou o conhecimento dos consumidos sobre os impactos causados pelo descarte incorreto de medicamos, em duas cidades da Grande SP, e também apontou que a maioria da população consome algum tipo de medicamento $(90 \%)$ e descartam de maneira inadequada os medicamentos, seja no lixo comum, ou em pia, ralo ou vaso sanitário: (84\%) em Guarulhos e (92\%) em Itapevi.

Segundo Miranda et al. (2018) "[...] a principal forma de entrada de resíduo de medicamentos no meio ambiente é por meio do lançamento direto de medicamentos na rede de esgotos domésticos tratados ou não em cursos de água". Segundo os autores (p.581) "[...] o descarte inadequado é feito pela maioria das 
pessoas por falta de informação e divulgação sobre os danos causados pelos medicamentos ao meio ambiente e por carência de postos de coleta".

Neste contexto, o Brasil deve encarar o problema e promover um diálogo aberto que busque possíveis soluções para reverter à situação e mitigar os riscos ambientais causados pelo descarte inapropriado de medicamentos.

Para sanar a falta de informação da população, quanto ao método, condutas para o descarte correto de medicamento e ao impacto que pode provocar no meio ambiental, Souza et al. (2015) afirmam que "[...] são fundamentais ações integradas entre os diversos setores e a conscientização da população estimulando sua participação em atividades voltadas à educação ambiental e ao uso correto do medicamento". Gasparini et al. (2011) sugerem “[...] a implantação de projetos municipais que visem orientar a população quanto ao uso e ao descarte correto dos medicamentos".

Os profissionais de saúde também podem colaborar na disseminação dos riscos ambientais e do descarte correto, conforme Ramos et al. (2017):

[...] educar os pacientes sobre a destinação adequada é um dos passos mais importantes e os profissionais de saúde envolvidos no processo do cuidado devem incentivar seus pacientes sobre o uso racional e descarte adequado dos medicamentos e de todos os RSS que conferem riscos sanitários e ambientais.

Outro ponto a considerar seria a definição de locais para a coleta e, consequentemente, o descarte adequado. Para Balbino et al. (2012):

[...] a população e os governos devem atuar de forma conjunta para a solução desse grave problema ambiental, através da criação de pontos para coleta dos remédios para serem encaminhados ao descarte adequado, passando, assim, a ser responsabilidade das farmácias e drogarias a destinação também desses medicamentos.

Miranda et al. (2018, p.583) acreditam que "[...] seria essencial realizar campanhas de esclarecimento e conscientização da população das próprias autoridades sobre a importância do assunto[...] ", já Cruz et al. (2017, p.88) sugerem como solução “[...] ações de educação que promovam o uso racional dos medicamentos, a implementação de sistemas de coleta para o descarte seguro, em serviços de saúde públicos ou privados [...]", evitando o acúmulo de medicamentos nos domicílios e a poluição do meio ambiente.

\section{CONCLUSÕES}

Por meio da pesquisa bibliográfica, conclui-se que a maioria da população brasileira tem medicamentos em casa e descartam seus resíduos de forma inadequada, carecendo de informação sobre o descarte apropriado. Alguns dos fatores que contribuem para a geração desnecessária de resíduos de medicamentos por parte da população são: hábitos de consumo, automedicação e propaganda agressiva.

Entre os problemas ambientais caudados pelo descarte inadequado de resíduos de medicamentos, pode-se destacar: degradação do solo, contaminação das águas, poluição do ar, proliferação de bactérias e alteração de ecossistemas.

É necessário promover ações de educação ambiental, campanhas de conscientização da população 
sobre o consumo racional e o descarte apropriado de medicamentos. Os profissionais de saúde também podem atuar como disseminadores de informações sobre os riscos ambientais causados pelo descarte inapropriado, orientando os usuários de medicamento sobre a forma correta.

A Política Nacional de Resíduos Sólidos, instituída em 2010, estabeleceu a responsabilidade compartilhada e logística reversa para os gerados de resíduos, mas foi omissa quanto a obrigatoriedade destes recolherem os fármacos que sobram ou vencem dos produtos vendidos. Assim sendo, a legislação precisa ser revista, estabelecendo os responsáveis pela logística reversa dos medicamentos vendidos à população. Uma solução para o descarte seguro é a criação de um sistema de coleta, e ações governamentais que difundam esse sistema. Outra possibilidade, para divulgação quanto ao descarte adequado de medicamentos, é conter a informação na bula do medicamento.

\section{REFERÊNCIAS}

ABNT. Associação Brasileira de Normas e Técnicas. NBR 12.808/1993: classifica os resíduos de serviços de saúde quanto aos riscos potenciais ao meio ambiente e à saúde pública, para que tenham gerenciamento adequado. Rio de Janeiro: ABNT, 1993.

BALBINO, M. L. C.; BALBINO, E. C.. O descarte de medicamentos no Brasil: Um olhar socioeconômico e ambiental do lixo farmacêutico. Revista Brasileira de Estudos Jurídicos, v.7, n.1, p.87-100, 2012.

BRASIL. Ministério da Saúde. Agência Nacional de Vigilância Sanitária. Manual de gerenciamento de resíduos de serviços de saúde. Brasília: Ministério da Saúde, 2006.

BRASIL. Ministério do Meio Ambiente. Política Nacional de Resíduos Sólidos. Brasília: MMA, 2019.

BRASIL. Lei n. 12.305, de 2 de agosto de 2010. Institui a Política Nacional de Resíduos Sólidos; altera a Lei no 9.605, de 12 de fevereiro de 1998; e dá outras providências. Brasília: DOU, 2010.

CAMPANHER, R.. Descarte adequado de medicamentos: percepção socioambiental do empresário de drogarias frente à Logística Reversa. Dissertação (Mestrado em Educação, Ambiente e Sociedade) - Centro Universitário das Faculdades Associadas de Ensino, São João da Boa Vista, 2016.

COSTA, D. A. O.. Diagnóstico do sistema de coleta de resíduos de medicamentos pós-uso na cidade de Natal/RN. Monografia (Bacharelado em Engenharia Ambiental) Universidade Federal do Rio Grande do Norte, Natal, 2019.

CRUZ, M. J. B.; AZEVEDO, A. B.; CRUZ, H. L.; BODEVAN, E. C.; ARAUJO, L. U.; SANTOS, D. F.. Descarte de medicamentos em municípios do Vale do Jequitinhonha, Minas Gerais, Brasil. Vigilância Sanitária em Debate: Sociedade, Ciência e
Tecnologia, v.5, n.1, p.85-90, 2017. DOI: https://doi.org/10.22239/2317-269x.00802

GASPARINI, J. C.; GASPARINI, A. R.; FRIGEIRI, M. C.. Estudo do descarte de medicamentos e consciência ambiental no município de Catanduva- SP. Revista Ciências \& Tecnologia, v.2, n.1, p.38-51, 2011.

MARCONI, M. A.; LAKATOS, E. V.. Fundamentos de Metodologia Científica. 7 ed. São Paulo: Atlas, 2010.

MIRANDA, A. C.; PRAZERES, K. C.; KLEPA, R. B.; FRANCO, M. A. C.; SILVA FILHO, S. C.; SANTANA, J. C. C.. Avaliação do conhecimento dos consumidores de duas cidades da Grande $\mathrm{SP}$, Brasil, sobre os impactos causados pelo descarte incorreto de medicamentos. Revista Interciencia, v.43, n.8, p.580-584, 2018.

RAMOS, H. M. P.; CRUVINEL, V. R. N.; MEINERS, M. M. M. A.; QUEIROZ, C. A.; GALATO, D.. Descarte de medicamentos: Uma reflexão sobre os possíveis riscos sanitários $\mathrm{e}$ ambientais. Revista Ambiente \& Sociedade, v.20, n.4, p.145168, 2017. DOI: https://doi.org/10.1590/18094422asoc0295r1v2042017

SOUZA, C. D. F. A.; FALQUETO, E.. Descarte de Medicamentos no Meio Ambiente no Brasil. Revista Brasileira Farmácia, v.96, n.2, p.1142-1158, 2015.

VATOVEC, C.; VAN WAGONER, E.; EVANS, C.. Investigating sources of pharmaceutical pollution: Survey of over-thecounter and prescription medication purchasing, use, and disposal practices among university students. Journal of Environmental Management, v.198, p.348-352, 2017. DOI: https://doi.org/10.1016/j.jenvman.2017.04.101

ZIRABA, K.; HAREGU, T. N.; MBERU, B.. A review and framework for understanding the potential impact of poor solid waste management on health in developing countries. Archives of Public Health, v.74, n.1, p.1-11, 2016.

A CBPC - Companhia Brasileira de Produção Científica (CNPJ: 11.221.422/0001-03) detém os direitos materiais desta publicação. Os direitos referem-se à publicação do trabalho em qualquer parte do mundo, incluindo os direitos às renovações, expansões e disseminações da contribuição, bem como outros direitos subsidiários. Todos os trabalhos publicados eletronicamente poderão posteriormente ser publicados em coletâneas impressas sob coordenação da Sustenere Publishing, da Companhia Brasileira de Produção Científica e seus parceiros autorizados. Os (as) autores (as) preservam os direitos autorais, mas não têm permissão para a publicação da contribuição em outro meio, impresso ou digital, em português ou em tradução. 